\title{
Pedagogical excellence in the focus of research at Russian universities
}

\author{
Emmanuil Bagramyan ${ }^{1 *}$, Elena Sakharchuk ${ }^{1}$, and Elena Volya $^{1}$ \\ ${ }^{1}$ Russian Academy of Education, 119121, Moscow, Russian Federation
}

\begin{abstract}
The article presents the results of systematizing the subject areas of psychological and pedagogical researches in 2016-2020, dedicated to generalizations of the reflexively advanced Russian pedagogical practice in the context of the competence characteristics of pedagogical skills accentuation. We analyzed reports on the activities of scientific centers of the Russian Academy of Education, materials of scientific conferences and publications in the reference area of large Russian universities, as well as the regulations of pedagogical excellence competitions. To describe the concept of pedagogical excellence as a theoretical concept, the general orientation of the ideas of the most authoritative authors in psychological and pedagogical science was synthesized: pedagogical excellence is the highest level of a teacher's ability to involve students in joint educational activities to achieve the planned results of development, education and training. The main vectors of differentiation of scientific directions are determined, based on: 1) a personality-oriented model of the teacher formation in the conditions of modern Russian education transformations; 2 ) the pragmatic and technological model of the pedagogical excellence formation. Interdisciplinary studies are identified as promising, integrating a personality-oriented approach and elements adapted to Russian conditions: 1) western technological pedagogical approaches, 2) the experience of Soviet pedagogy.
\end{abstract}

\section{The problem of essence identifying of pedagogical excellence and multiplication of outstanding pedagogical achievements}

Pedagogical excellence as a scientific category is widely reflected in modern Russian studies related to the scientific fields of pedagogy and psychology. However, the sociocultural and institutional aspects of pedagogical excellence in the context of current trends and challenges have been studied very little, primarily due to the ongoing transformations over the past decades both in the organizational system of education and in the structure and content of educational activities of organizations of different levels of education, in this connection, a full-fledged definition and construction of an ideal model of a modern teacher causes difficulties. Separate research teams conduct scattered research in the subject area, the initial methodological approaches of these studies may be different.

\footnotetext{
* Corresponding author: er.bagramyan60@gmail.com
} 
At the same time, the competence-based model of the "master of pedagogy", focused on fulfilling the acutely urgent tasks of Russian education and corresponding to today's ideas about the comprehensively developed personality of a professional (in the context of the mainstream of humanization of education) is in demand - both from the side of methodologists-developers of educational content of different levels, and on the side of the heads and teachers of educational organizations of general, secondary vocational and higher education.

Professional and universal competences of teachers (of different levels of education), reflected in the relevant professional standards, do not quite obviously reflect the competence model of a teacher demanded by society, corresponding to the ideas of a professional with a high degree of personal responsibility for the results of the work performed, constantly developing, having creative potential and appropriate motivation.

The lack of systematization of reflexive advanced pedagogical practice in the context of accentuation of the competence characteristics of the model of the highest level specialist in pedagogy narrows the possibilities of multiplying pedagogical achievements and their introduction into teaching technologies, which in general negatively affects the improvement of the Russian education quality.

\section{Research of the pedagogical excellence problems in Russian psychological and pedagogical science}

In most Russian psychological and pedagogical sources, the concept of "pedagogical excellence" is used without specifying its essential characteristics, which greatly complicates the description of pedagogical excellence as a theoretical concept. However, there are theoretical developments by authors recognized in psychological and pedagogical science $[1,2,3,4,5,6,7]$, which allow us to synthesize the general orientation of these ideas in the following definition: pedagogical excellence is the highest level of a teacher's ability to involve students in a joint educational activities to achieve the planned results of development, education and training.

Certain researches of modern Russian scientists represent a generalization of the prevailing ideas and experience in the reference area, such as, for example, research in the field of trends and prospects for the development of a system for improving the teachers' professional excellence (materials of Irkutsk State University conferences [8,9]), research of the modern system of pedagogical excellence development in the context of global trends [10]. At the same time, it can be argued that until now there have been no researches related to the systematization of the pedagogical excellence' scientific potential at the national level.

\section{Purpose and objectives of the research}

The purpose of the research is to determine the main directions and identify the subject areas of research in the field of pedagogical excellence conducted by leading Russian universities, as well as to identify existing gaps and promising tasks of scientific research. The initial basis of the research was: systematized over 4 years (2016-2020) reports on research conducted by scientific centers of the Russian Academy of Education (federal and regional levels, representing various constituent entities of the Russian Federation), as well as the studies of large Russian universities in the context of their scientific interest in the subject area related to pedagogical excellence in the conditions of modern Russia.

During the research, the topics of scientific events (symposia, forums, conferences and round tables) held in the designated period of time were studied, as well as the regulations 
of professional excellence competitions among teachers of different levels of education, as well as publications of scientists-representatives of scientific centers of the Russian Academy of Education in scientific peer-reviewed publications in the context of reference topics. The objectives of the research were: systematization and analytical processing of initial data, identification of the main directions of scientific research in the reference area, identification of problem areas and promising areas of scientific research of pedagogical skill.

\section{Scientific results and recommendations for use}

Analysis of the initial data showed that the interest of researchers in the problems of pedagogical excellence is obvious. The annual and quarterly structuring of the reports of scientific centers, as well as a fairly long period covered by the research, familiarization with the problems of scientific research of large Russian universities (the results of which are published and indexed in the national citation base of the RISC) of the last 3 years made it possible to consider the genesis of the conceptual apparatus, the dynamics of research, and also take into account the influence of various factors (such as: changes in the organizational model of the education system, the adoption of educational standards, the start of competitions for young professionals World Skills, etc.).

In the mainstream of the humanization of education, it is planned to activate research interests in the plane of the personality-oriented paradigm of the modern teacher formation (Nizhny Novgorod State University); subject-oriented approach to supporting the professionalization of a teacher and identifying motivational factors for choosing a teacher's profession (Tula State Pedagogical University).

Sociocultural shifts in society determine the problems of scientific research on topics that are acutely relevant for the Russian pedagogical community [11]. Thus, scientific reflection is noted in connection with the rethinking of the principles of continuous improvement of the teachers' professional excellence (Astrakhan State University); a competence model is being developed - idealization of a teacher-master: models of teachers' individual competencies are being designed (for example, the competence of forming students' healthy lifestyle, Ivanovo State University); criteria for successful pedagogical interaction are being developed in order to improve pedagogical skills (Astrakhan State University); approaches to the problem of the modern pedagogical style formation are substantiated (St. Petersburg State Pedagogical University), etc.

There are reasons to point out some signs of the development of a national institution of pedagogical excellence; this fact is indicated by the festivals of the best pedagogical practices and innovations held by the RAS scientific centers (for example, the Tver Scientific Center of the RAS).

In the context indicated above, one should consider modern research devoted to: the essence of pedagogical assistance to the development of professional excellence (Chechen Institute for Advanced Training of Educators); organizational, managerial and methodological foundations of the centers for continuous professional development (Academy of Social Management, Moscow; Krasnodar and Tyumen Institutes of Education Development, etc.); analysis of effective teaching experience (for example, at the Belgorod State Institute of Arts and Culture, at the Kemerovo State University, the Kuban State University, etc.).

At the same time, new researches emerging in the context of pragmatization and technologization of educational activities [12] are of interest: modeling the training of competitive graduates of pedagogical universities (Tula State Pedagogical University, Oryol State University, etc.); qualimetric monitoring of pedagogical skills (Kuban State University, etc.). 
Along with the researches of pedagogical excellence on the Russian experience and on the basis of Russian classical approaches to understanding its essence as a derivative of comprising it three groups of competencies: related to oneself, to interaction with other people, to activities (I.A. Zimnyaya [13]). Russian scientific centers conduct joint research with foreign partners aimed at introducing elements of Western teaching models into Russian practice (for example, research by the Vocational Pedagogical University in Yekaterinburg and other large universities under international Erasmus + grants dedicated to the training of teachers for the vocational education and training system) $[14,15]$. A number of scientific centers are studying models of preparing students of pedagogical colleges for the WorldSkills Russia championships: Early Childhood Education "Preschool education", RU Elementary School Teaching "Teaching in elementary grades") (Southern Federal University, Bryansk State University, etc.).

In the context of the foregoing, attention is drawn to the insignificantly expressed interest of Russian researchers in rethinking the Russian pedagogical experience, which proved to be successful in the past (under the Soviet education system). There are separate contemporary researches of the history of pedagogical excellence in Russia (for example, Kuban State University).

In our opinion, the problem area that requires the attention of researchers is insufficient knowledge of the processes of multiplication of pedagogical achievements and their implementation in teaching technologies.

\section{Conclusions and prospects for further research}

The conducted research allows us to assert that the problem of pedagogical excellence is of general interest to the Russian academic community, first of all, in the context of its formation in the process of teachers' professionalization. In the ongoing research, there have been signs of two main scientific directions, differentiating according to the fundamental methodological vector: 1) based on the classical psychological and pedagogical model of the formation of a teacher-master-personality in the context of transformations of modern Russian education; 2) based on the pragmatic and technological model of the pedagogical excellence formation. Interdisciplinary researches that integrate the reliance on the classical model along with adaptation for Russian conditions, both elements of Western technological pedagogical experience and the experience of Soviet pedagogy, primarily in the field of project learning and collective forms of educational activity, seem to be promising in the subject area.

\section{References}

1. K.D. Ushinsky, Human being as a subject of education (2014)

2. A.S. Makarenko, My education system. Pedagogical poem (2016)

3. S.L. Soloveychik, Education by Creativity (1978)

4. A.M. Novikov, I am an Educator (2011)

5. V.A. Suhomlinsky, One Hundred Tips for Teacher (2011)

6. P.P. Blonsky, Psychology and pedagogy. Selected Works (2016)

7. O.V. Beskrovnaya, A.V. Koroleva, Classical approaches to the problem of teaching excellence in a modern interpretation, Materials of the X All-Russian Scientific and Practical Internet Conference, 29-33 (2019)

8. A.K. Suleymanova, E.V. Ziyatdinova, The multilevel system of higher professional education: features and prospects, improving the professional skills of pedagogical 
workers in Russia: challenges of the time, trends and development prospects, Materials of the All-Russian scientific and practical conference with international participation, 44-49 (2019)

9. E.A. Krutova, Continuing education as a factor in the formation of human capital, improving the professional skills of pedagogical workers in Russia: challenges of the time, trends and development prospects, Materials of the All-Russian scientific and practical conference with international participation (2019)

10. M.V. Sidorova, The modern system of improving pedagogical excellence in higher education in the context of the world community, Scientific Bulletin of V.V. Lukyanov Oryol Law Institute of the Ministry of Internal Affairs of Russia, 4 (81) (2019)

11. E.S. Volya, On the (proto) philosophy of education, Bulletin of the Russian State Humanitarian University, Pedagogy Series. Psychology. Education, 2 (145), 113-128 (2015)

12. L.Yu. Gracheva, E.R. Bagramyan, M.N. Tsygankova, T.Ts. Dugarova, N.N. Sheveleva, Models and Practices of Professional Development of Teachers in Foreign Systems of Education, Education and Science, 22, 6, 178-193 (2020)

13. I.A. Zimnyaya, Pedagogical psycology (2010)

14. V.S. Tretyakova, Steps to the Future: Dual Learning and Networking in the Structure of Professional Education, Continuing Education: Theory and Practice of Implementation. materials of the III International Scientific and Practical Conference, 138-143 (2020)

15. S.V. Ogneva, E.S. Sakharchuk, Y.V. Kopylov, Conceptual approaches to organizational and methodological support systems and certification of qualifications, A. S. Science, 11, 14, 111-116 (2015) 